\title{
Solid particle erosion response of aluminum reinforced with tungsten carbide nanoparticles and aluminide particles
}

\author{
Ekaterini Chantziara ${ }^{1}$, Konstantinos Lentzaris ${ }^{1}$, Angeliki G. Lekatou ${ }^{1}$, and Alexander E. \\ Karantzalis ${ }^{1, *}$ \\ ${ }^{1}$ Laboratory of Applied Metallurgy, Department of Materials Engineering, University of Ioannina, \\ 45110 Ioannina, Greece
}

\begin{abstract}
The main concept behind this work is to further enhance the attractive properties of aluminum by fabricating $\mathrm{Al}$ - WC composites and evaluating them in terms of their solid particle erosion response. Aluminum Matrix Composites (AMCs) were produced by the addition of submicron sized WC particles (up to $2.5 \mathrm{vol} \%$ ) into a melt of Al1050. Casting was assisted by the use of $\mathrm{K}_{2} \mathrm{TiF}_{6}$ as a wetting agent and mechanical stirring in order to minimize particle clustering. Extensive presence of in-situ intermetallic phases $\left(\mathrm{Al}_{4} \mathrm{~W}, \mathrm{Al}_{5} \mathrm{~W}, \mathrm{Al}_{12} \mathrm{~W}, \mathrm{Al}_{3}(\mathrm{Ti}, \mathrm{W})\right.$, $\mathrm{Al}_{3} \mathrm{Ti}$ ) was observed in the cast products. Particle distribution was reasonably uniform comprising both clusters and isolated particles. Solid particle erosion experiments were carried out for impact angles of $30^{\circ}, 60^{\circ}$ and $90^{\circ}$, using angular $\mathrm{Al}_{2} \mathrm{O}_{3}$ particles as the eroding medium and under 5 bar spraying pressure. The erosion rate was calculated by measuring the mass loss and the eroded surfaces were examined with SEM-EDX. Increased erosion resistance was observed for low particle additions $(\leq 1.0$ vol\%WC). Finally, a possible erosion mechanism was proposed based on the material's microstructural and morphological characteristics.
\end{abstract}

\section{Introduction}

Interest in Aluminium Matrix Composites (AMCs) has grown as a great deal in recent years in different industrial sectors, including aerospace, defense and automotive since it is well known that the reinforcement with nano- and sub-micron particles can improve the mechanical properties through the synergistic action of several strengthening mechanisms [1]. The addition of ceramic reinforcement can significantly improve, among others, the strength, stiffness, wear resistance and high temperature properties [2-4]. The particulatereinforced AMCs (PRAMCs) are of particular interest due to their ease of fabrication, lower costs and isotropic properties.

In order to conserve the isotropic properties of the PRAMCs the main drawback that have to be overpassed, during casting process, is the tendency of the nanoparticles to agglomerate. An improvement of the particle-molten alloy wetting behavior could limit the

* Corresponding author: akarantz@cc.uoi.gr 
drawback of segregation. The current experimental effort adopts a combination of simple wettability improving measures, such as: (1) The use of wetting agents (commonly fluoride salts) that promote the intinate contact between ceramic particles and molten alloy by dissolving surface oxides [5-9], (2) the application of mechanical stirring that can support the favorable wetting characteristics of less than $90^{\circ}$ contact angle and provide the necessary shear forces for total particle insertion [10] and (3) the introduction of ceramic phases of strong metallic character, such as WC. Fabrication of AMCs reinforced by WC micro-particles by powder metallurgy and casting methods is currently receiving a growing research attention owing to a significant improvement of mechanical properties and increase in the wear resistance [11,12].

Concerning the tribological properties of AMCs, these are of major importance, since they have to satisfy the necessity of long-lasting applications. The expansion of AMCs applications' which are related to equipment in electrical or petroleum industry requires the investigation of their response in solid particle erosion. Solid particle erosion, a typical wear mode, is a process of progressive removal of material from a target surface that occurs in different machine parts due to the repeated impact of solid particles [13-22]. The effects of solid particle erosion, such as surface roughness, wear of components, surface degradation and reduction in the functional life of structure, have been recognized for a long time and it is a serious problem in many engineering systems [14-18]. It is a quite complex phenomenon, since it involves several processes. The main process is the mechanical impact, caused by the impingement of solid particles on the target material, secondary processes, like thermal, chemical and physical reactions between the counterparts are also taking place during erosion [19-22].

This work continues studies [23,24] within the framework of manufacturing competative PRAMCs by following four main directions: (a) adopting low cost, simple fabricating techniques, (b) using ceramic nanoparticles as primary additions to exploit the advantages of the ultra-fine size, (c) using low particle additions to reduce particle clustering and raw material costs and (d) pursuing secondary in-situ reinforcing particle formation for further property improvement. The present effort has two objectives: (a) to investigate the effect of $\mathrm{K}_{2} \mathrm{TiF}_{6}$ salt fluxe and mechanical stirring on the WC particle incorporation and the erosion behavior of the resulting AMCs and b) to determine the highest WC particle addition before the deterioration of erosion performance starts.

\section{Experimental Procedure}

AMCs were synthesized by the addition of submicron sized WC particles (200 - 400 $\mathrm{nm}$ ) into Al-1050 melt. The compositions employed were up to Al-2.5vol\%WC. Wetting and homogenization were assisted by fluxing $\left(\mathrm{K}_{2} \mathrm{TiF}_{6}\right.$ salt $)$ and mechanical stirring. Specimens were cut from each cast bar and standard metallographic procedures were carried out, which included grinding by $\mathrm{SiC}$ papers followed by polishing with diamond suspensions. The microstructural inspection of all specimens was performed by a scanning electron microscope (SEM - JEOL JSM 6510 LV) equipped with an Oxford Instruments XAct EDX Analyser. X-ray Diffraction (XRD) was carried out by the Bruker D8 Advance Diffractometer using a scanning rate of $0.01 \%$. The morphology of the AMCs was estimated by image analysis (Image $\mathbf{J}$ software).

Solid particle erosion tests, using a commercial sand-blasting chamber (M110 / DC600), were carried out at impact angles of $30^{\circ}, 60^{\circ}$ and $90^{\circ}$ using angular $\mathrm{Al}_{2} \mathrm{O}_{3}$ particles (up to $250 \mu \mathrm{m}$ ) as the erodent medium. The distance between the nozzle and the specimen was $10 \pm 1 \mathrm{~mm}$. The pressure of the sprayed erodent from the nozzle, on the surface of the sample, was 5 bar and the total duration of each spraying was $5 \mathrm{~min}$. All specimens were ethanol cleaned and weighted before testing. Test runs were interrupted 
every $1 \mathrm{~min}$ in order to record the material loss. The erosion rate was calculated from the mass loss versus the mass erodent of the experiment (triplicate runs). Lastly, erodent surfaces morphologies were examined using SEM/EDS analysis for further explanation.

\section{Results and discussion}

\subsection{Microstructural observations}

Successive particle incorporation was achieved in all the different composite production attempts, as it is illustrated in Fig. 1. Results are mostly associated with the use of $\mathrm{K}_{2} \mathrm{TiF}_{6}$ salt as a wetting agent that cleans the melt surface form oxide phases, allowing the reinforcing particles and the molten metal to express their wetting characteristics, as Karantzalis and Kennedy [25-27] originally established. The particle distribution can be characterized as fairly uniform, with clusters, being the major feature, which seems to become coarser and more extended as the reinforcement volume fraction increases.

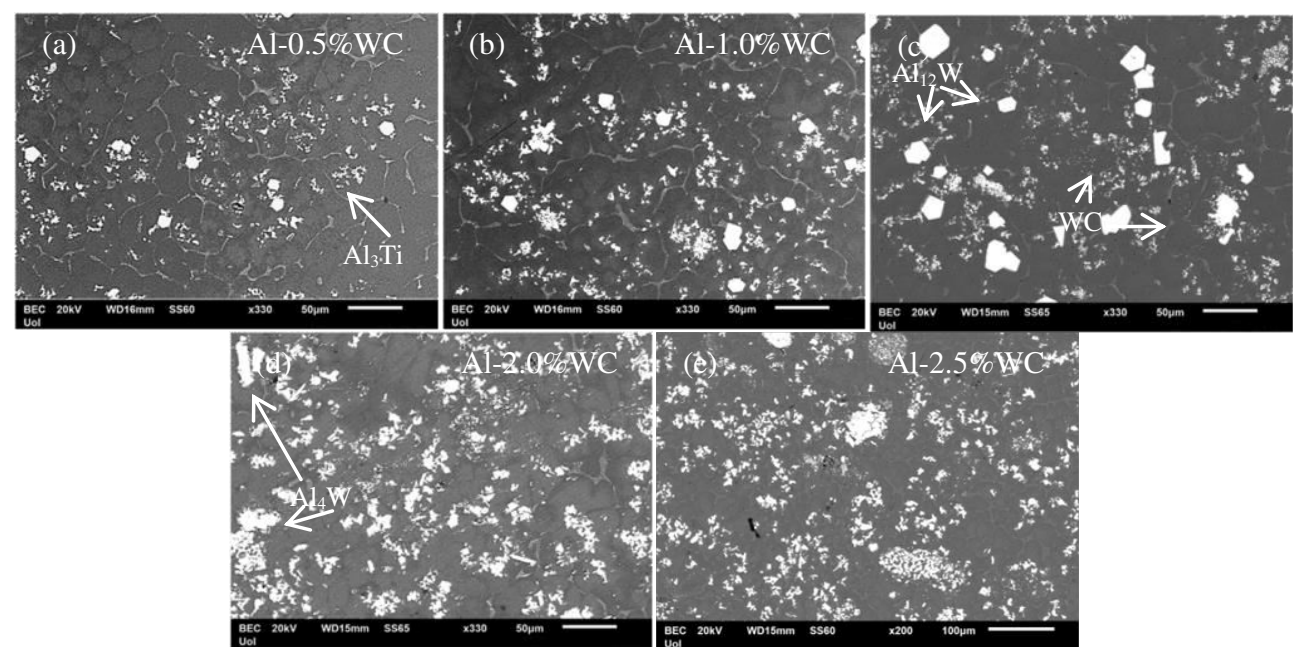

Fig 1 Low magnification backscattered electron (BEC) micrographs of the microstructure of produced AMCs (a) Al-0.5vol.\%WC, (b) Al-1.0vol.\%WC, (c) Al-1.5vol.\%WC, (d) Al-2.0vol.\%WC and (e) Al-2.5vol.\%WC.

Various precipitates are fairly evenly distributed, located both at the grain interior and boundaries, despite the reaction product extent. Various factors affect the distribution such as wetting behavior of the involved phases, solidification front - particle interactions, particle/cluster size and morphology, heat conductivity and density of the involved phases etc. Thus the final particle location is quite difficult to be absolutely predicted.

Image $\mathbf{J}$ software was utilized in order to assess the particle distribution and cluster tendency in the final cast microstructure. More specifically, through the use of SEM images, the percentage of surface covered by particles was measured for each individual composite composition. The theoretical particle coverage was calculated based on the following assumptions: (a) the distribution of particles was homogeneous throughout the cast specimens, i.e. no particle clustering occurred and constant particle distribution was maintained, (b) the particles were considered ideally as spheres of uniquely defined radius, (c) two cases of radii were considered according to the powder specification: an upper value of $400 \mathrm{~nm}$ diameter (i.e. radius $200 \mathrm{~nm}$ ) and a lower value of $200 \mathrm{~nm}$ (i.e. radius 100 $\mathrm{nm}$ ). These two values cover the range of powder particle size specification provided by the manufacturer and (d) the surface coverage was calculated assuming that the surface plane intersects the involved particles at the maximum area i.e. at the hemisphere. 
Based on these assumptions, Fig. 2 shows the theoretical surface coverage for $200 \mathrm{~nm}$ and $100 \mathrm{~nm}$ radius particles in relation with the particle vol. content as well as the actually measured particle area coverage. Value of experimental coverage area close to the lower theoretical surface coverage values implies a higher tendency for clustering. In general, the experimental results are in accordance with the limits, which steam from the theoretical predictions. It appears that, reinforcing particles tend to formulate clusters of radius either about $100 \mathrm{~nm}$ or $200 \mathrm{~nm}$. In such a way, isolated particle's surface free energy declines and the formation of clusters consisted of a coarse particle in the middle surrounded by smaller ones occurs. However, this is not apparent in the case of lower compositions, which may indicates the fact that the less the amount of particles, the more decreasing their tendency to form clusters.

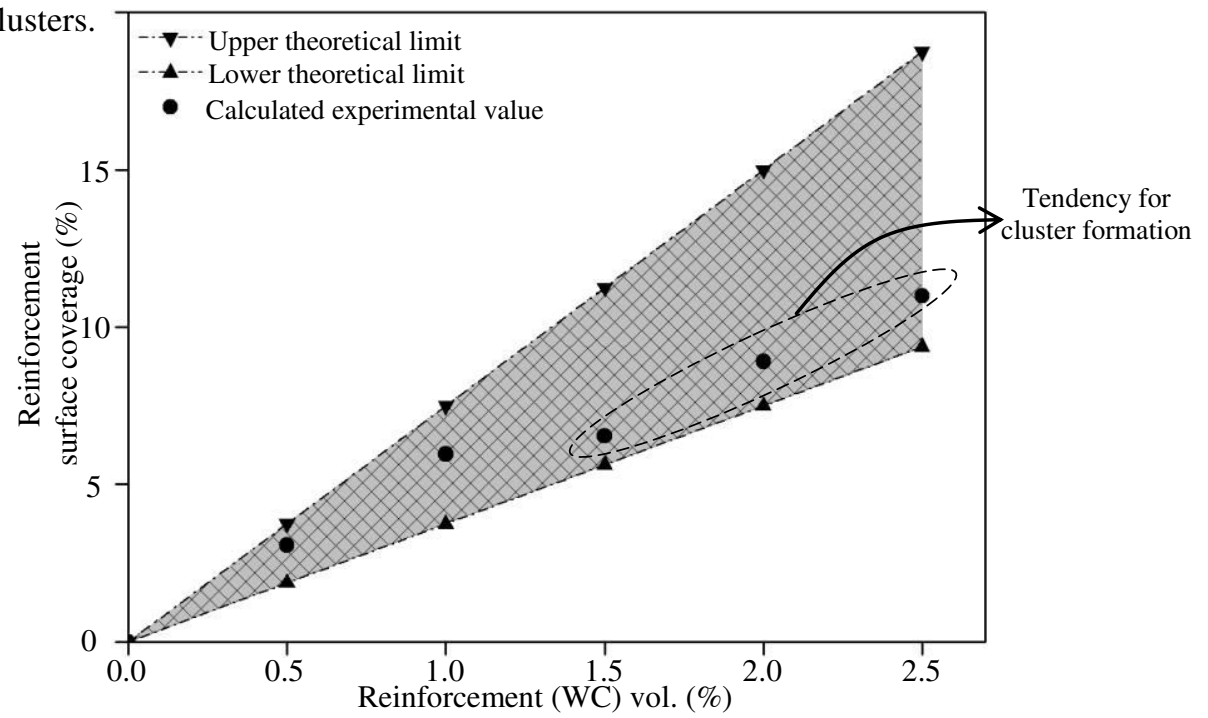

Fig 2 Diagram of surface coverage area $(\%)$ vs. reinforvement vol.\% which indicates the high tendency of WC nanoparticles to form clusters as their concetration increases.

In order to discuss the effect of $\mathrm{K}_{2} \mathrm{TiF}_{6}$ on the attained microstructures, one has to consider the reactions taking place during the whole manufacturing process. The present experimental results are in accordance with the Al-Ti [28], Al-W [29] and Ti-W [30] phase diagrams and the work of El-Mahallawy [31] and Lekatou et al.[23,24]. Fig. 3 and Fig. 4 present the microstructure of the produced AMCs which in combination with the XRD analysis (not presented here) and the EDX analysis, verify not only WC (ex-situ reinforcement) reinforcing particles, but also the existence of intermetallic phases (in-situ reinforcement). Three types of tungsten aluminide were observed: $\mathrm{Al}_{5} \mathrm{~W}$ and $\mathrm{Al}_{4} \mathrm{~W}$ in the form of acicular plates and $\mathrm{Al}_{12} \mathrm{~W}$ in the form of coarse polygonal particles, as a result of the sequence of peritectic reactions that took place on cooling [23,24]. A variety of different aluminide morphologies can result from the interaction of the $\mathrm{Al}$ - melt with the salt flux. $\mathrm{Al}_{3} \mathrm{Ti}$ phase is the most frequently found as clusters or agglomerates of fine rounded particles or coarse rectangular plates, especially inside $\mathrm{Al}$ grains which is justified by the previously mentioned reactions. $\mathrm{Al}_{3}(\mathrm{Ti}, \mathrm{W})$ phase can be found in the form of dispersed clusters of cuboidal platelets. Another important feature, is the presence of the eutectic micro - constituent, apart from $\mathrm{Al}$, that consists of $\mathrm{Al}-\mathrm{Fe}$ and $\mathrm{Al}-\mathrm{Fe}-\mathrm{Si}$ intermetallic phases, due to the presence of $\mathrm{Fe}$ and $\mathrm{Si}$ as the main impurities of the monolithic alloy, as Lekatou et al $[23,24]$ have also mentioned. Recently, this phase was identified as orthorhombic $\mathrm{Al}_{3} \mathrm{FeSi}_{2}$ (or $\delta$-AlFeSi) [32].

Despite the significant reactivity between the involved phases which is most likely responsible for the various different precipitate morphologies, particle distribution was 
considered as reasonably uniform comprising both clusters and isolated particles. In all cases, a morphological variety of different precipitates can be observed, such as: 1) fine size isolated particles, 2) fine size particle clusters, 3) coarse particle clusters, 4) blocky precipitates and 5) acicular plate like precipitates.
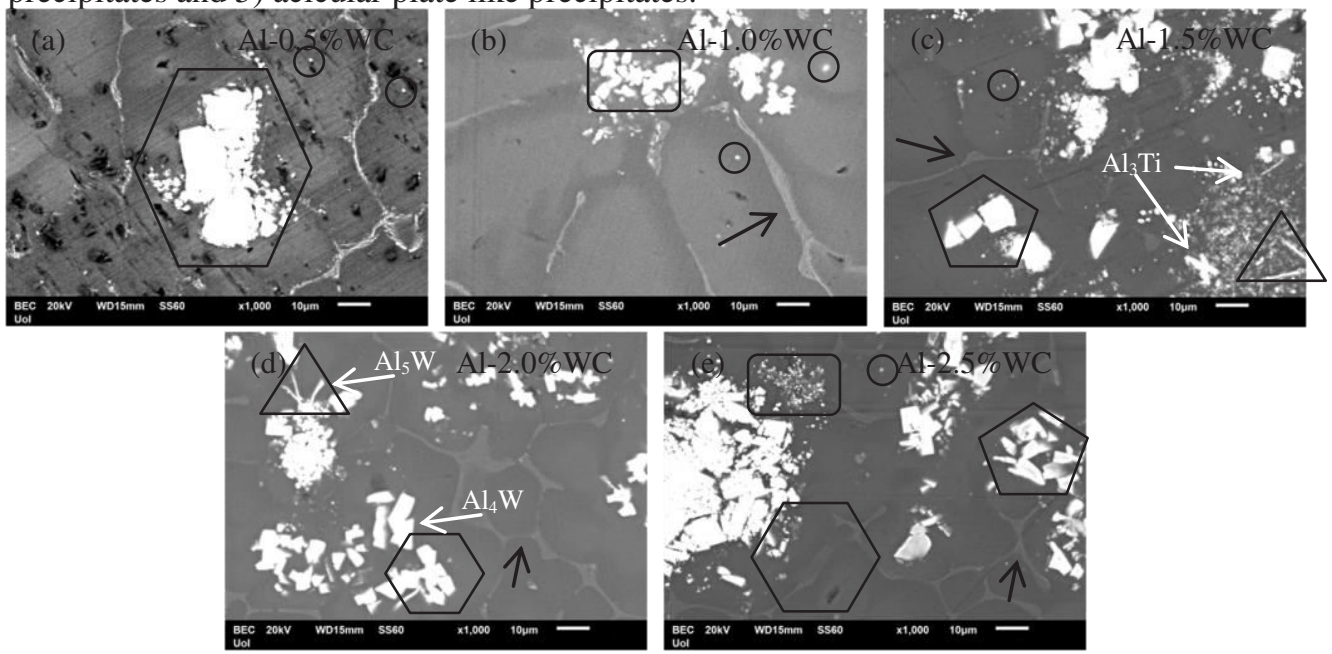

Fig 3 High magnification backscattered electron (BEC) micrographs of the microstructure of produced AMCs (a) Al-0.5vol.\%WC, (b) Al-1.0vol.\%WC, (c) Al-1.5vol.\%WC, (d) Al-2.0vol.\%WC and (e) Al-2.5vol.\%WC.(the different geometrical shapes indicate the ex-situ and in-situ reinforcements whereas the black arrows point out the eutectic micro - constituent)

Fig. 4 presents a typical SEM -EDX map analysis of the various morphological precipitate features in the $2.0 \mathrm{vol} \% \mathrm{WC}$ reinforced material, yet being observed in all the different composites.

Al K $\alpha 1$

Ti Ka1
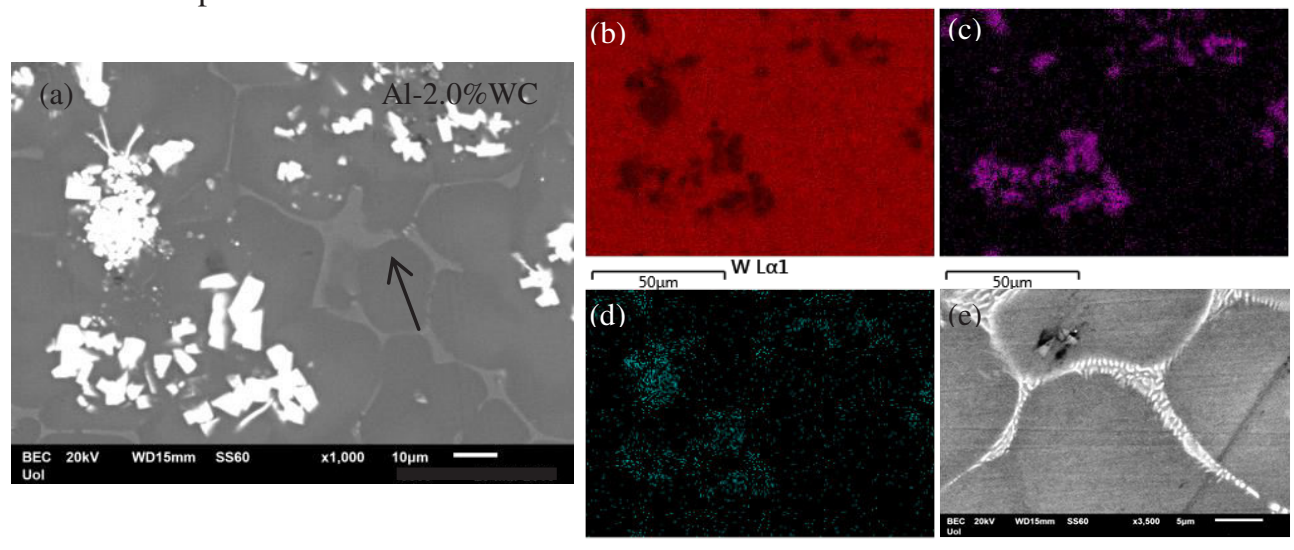

Fig 4 Micrograph of the microstructure of the produced Al-2.0vol.\%WC composite (a) with the corresponding EDX mapping analysis (b to d) and (e) higher magnification micrograph of the eutectic micro-constituent.

\subsection{Solid particle erosion response}

Fig. 5 presents the erosion rates of the different materials tested in the present effort. The solid particle erosion measurements have shown that the erosion behavior of the produced AMCs is governed by the behavior of the $\mathrm{Al}$ matrix, thus the metallic character of the examined AMCs is maintened. The highest erosion rate was observed in the case of impingement angle of $30^{\circ}$ and the minor at impingement angle of $90^{\circ}$. It is observed that as 
the impingement angle increases the erosion rate decreases; a typical behavior that is common in metals which exhibit ductile erosion behavior [14-16].

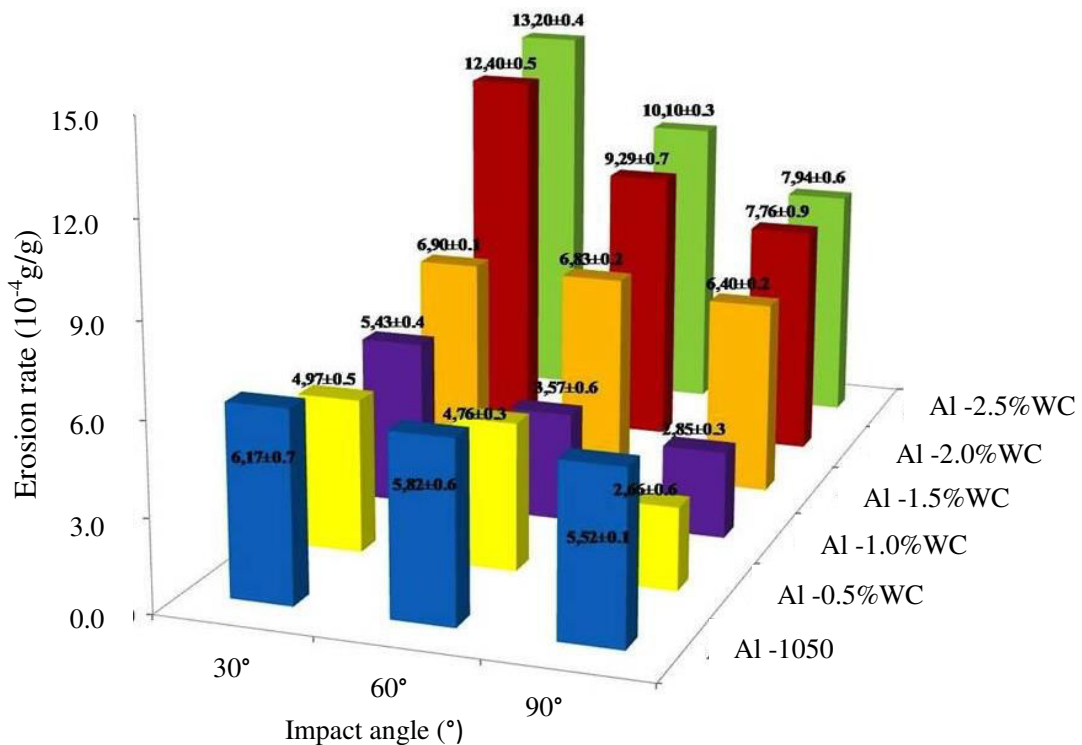

Fig 5 Summarized diagram of erosion rates as a function of impact angle and the volume fraction of all cast composites.

However, a decrease in the erosion rates is observed in the cases of $\mathrm{Al}-0.5 \mathrm{vol} \% \mathrm{WC}$ and $\mathrm{Al}-1.0 \mathrm{vol} \% \mathrm{WC}$ and an increase in the cases of $\mathrm{Al}-1.5 \mathrm{vol} \% \mathrm{WC}, \mathrm{Al}-2.0 \mathrm{vol} \% \mathrm{WC}$ and Al-2.5vol\%WC. Such behavior is propably attributed to the effect of WC additions. The higher additions seem to deteriorate the erosion performance considerably. As such, two different categories of materials behavior can be identified: A) of lower WC additions with enhanced erosion performance and $\mathrm{B}$ ) of higher WC additions with deteriorated erosion performance. More analytically, in class A, the better distribution of reinforcing particles (fewer clusters / agglomerates) led to slightly decreased material loss, while carbide and intermetallic compound particles restricted matrix flow. The situation, however, is altered in class B; the extensive particle clustering has led to extensive material loss.

A useful tool for further explanation of erosion testing is the examination of eroded areas via SEM. The panoramic view of the eroded surfaces for the three different impact angles and three representative material compositions (Al- $0.5 \mathrm{vol} \% \mathrm{WC}, \mathrm{Al}-1.5 \mathrm{vol} \% \mathrm{WC}$ and $\mathrm{Al}-2.5 \mathrm{vol} \% \mathrm{WC}$ ), is presented in Fig.6, which seem to verify the speculations conducted by the erosion rates experimental findings.

Closer examination of the eroded surfaces revealed that, in the impingement angle of $30^{\circ}$ severe plastic deformation caused the formation of intensive grooves with subsequent side-flaw of material and the particles either remove a chip, as in metal cutting, or leave material piled up at the sides or at the crater's end. As impact proceeds, these piled up areas will eventually be detached from substrate, making this detachment the dominant mass loss mechanism. In the impingement angle of $90^{\circ}$, heavy plastic deformation caused by vertical erodent impact was the dominant mechanism, which led to the maximum erosion rates. Here it should be noted that, other mechanisms such as brittle behavior due to work hardening, fragmentation of particles, low cycle fatigue, temperature effects due to high strain rates, delamination wear and extrusion mechanisms [33] also possibly took place and therefore defined the materials behavior. Finally, in the impingement angle of $60^{\circ}$, a combination of mechanisms which are present at impact angle $30^{\circ}$ and $90^{\circ}$ caused severe plastic deformation and lip detachment. 


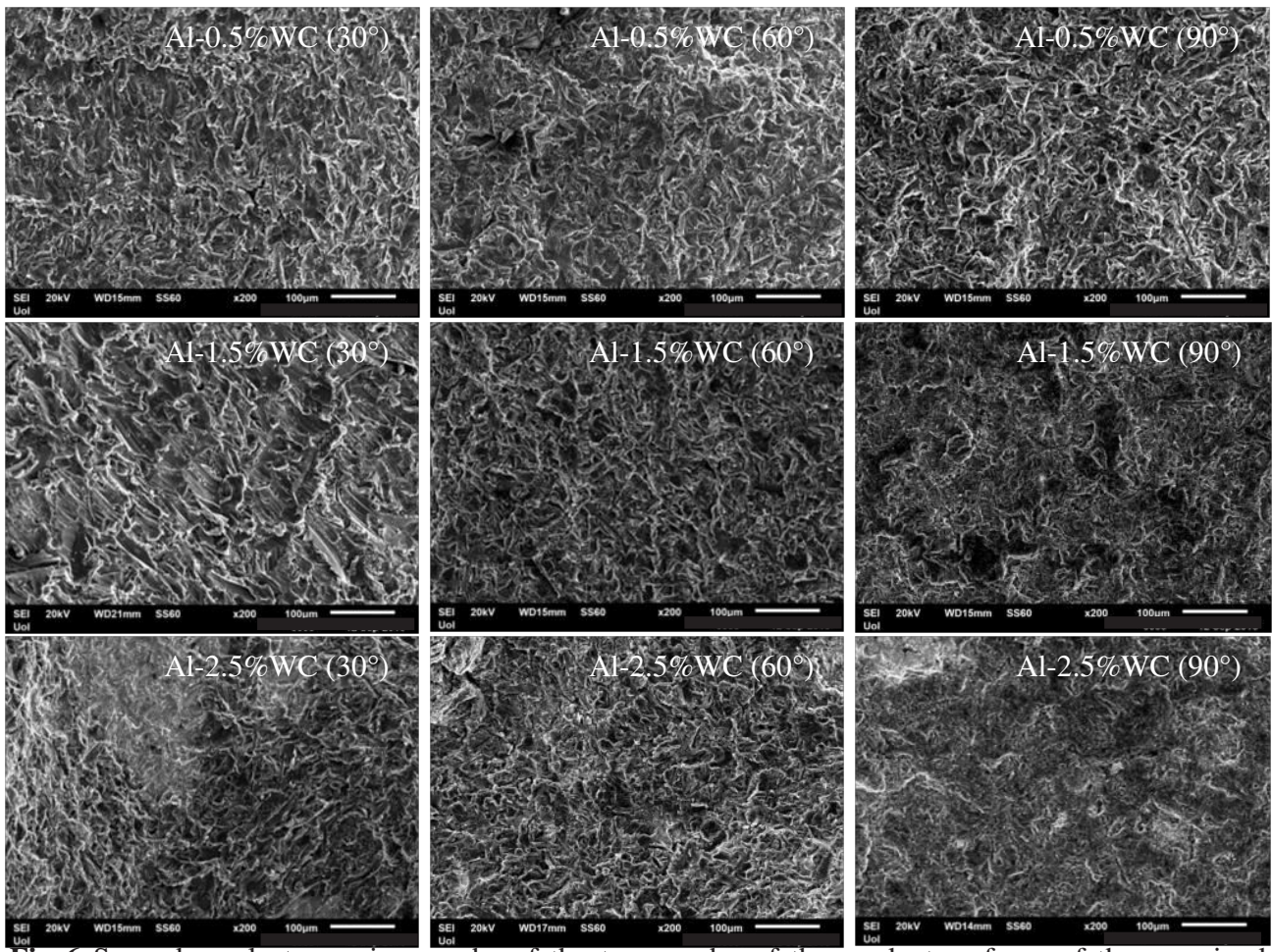

Fig 6 Secondary electron micrographs of the topography of the erodent surfaces of the examined AMCs under different impingement angles of erodent particles.

Based on the forementioned results, a possible mechanism can be proposed: (1) On the onset of solid particle erosion testing the ductile $\mathrm{Al}$ matrix is subjected to intensive plastic deformation and significant material flow occurred (ploughing) leading to the characteristic "crater - lip" morphology, (2) Subsequently, striking forces (vertical and horizontal), depending on erodent particle impingement angle defined the erodent area morphology. More analytically: (a) in the impingement angle of $30^{\circ}$, the strike force can be analyzed in two components, horizontal and vertical. The amplitude of horizontal component, which provokes material removal, is bigger than the amplitude of vectical component, whose incident is the impulse force and absorbed by ductile material. Thus the creation of a shallow crater and extensive lip formation are established, (b) in the impingement angle of $60^{\circ}$, the erosion rate was slightly reduced most likely due to the increased contribution of the vertical force of the impact force which is considerably absorbed by the ductile substrate. The erodent area morphology characterized by deeper crater than in the impingement angle of $30^{\circ}$, but the lip formation was more restricted in that case and (c) in the impingement angle of $90^{\circ}$, there was no horizontal component and the erodent area surface consisted of the deepest crater and the lip formation was minimized. (3) As the erosion test continues, the impact forces, the consecutive impact of alumina particles and the probable thermal fatigue caused the formation of cracks, (4) Crack propagation and growth eventually led to material removal. Crack propagation was delayed by the carbide / intermetallic phase dispersion and the refined a - $\mathrm{Al}$ grain boundaries in additions up to 1.0 vol\% WC. The situation, however, was altered in the case of higher WC additions, due to the extensive particle clustering. Possibly the fragmentation of reinforcement particles and the increase of crack propagation induced extensive material loss and (5) The accumulation of cracks led to the formation of a «new» area of surface to be eroded and the cycle was repeated. 


\section{Conclusions}

In the present study, aluminium matrix composites (AMCs) have been prepared by the addition of submicron sized WC particles into Al-1050 melt. The compositions employed were up to Al-2.5vol\%WC. Wetting and homogenization were assisted by fluxing $\left(\mathrm{K}_{2} \mathrm{TiF}_{6}\right)$ and mechanical stirring. The main conclusions drawn from the study of the microstructure and solid particle erosion performance of the composite materials are:

- The AMC contained two types of reinforcement: (a) WC nanoparticles and (b) in-situ intermetallic particles $\left(\mathrm{Al}_{4} \mathrm{~W}, \mathrm{Al}_{5} \mathrm{~W}, \mathrm{Al}_{12} \mathrm{~W}, \mathrm{Al}_{3}(\mathrm{Ti}, \mathrm{W}), \mathrm{Al}_{3} \mathrm{Ti}\right.$,). Particle distribution was considered as reasonably uniform comprising both clusters and isolated particles.

- Solid particle erosion behavior of the AMCs was governed by the Al-matrix; Increased erosion resistance was observed for low particle additions ( $\leq 1.0 \mathrm{vol} \% \mathrm{WC})$.

- An erosion mechanism was formulated and the erosion mode can be characterized as «severe» due to extremely aggressive testing conditions.

- The attained microstructures can fully explain the proposed mechanisms during solid particle erosion testing.

\section{References}

1. R. Casati, M. Vedani, Metals 4, 65 (2014)

2. A. Mortensen, I. Jin, Int. Mater. Rev. 37, 101 (1992)

3. K.U.Kainer, Metal Matrix Composites, Custom-Made Materials for Automotive \& Aerospace, Wiley (2006)

4. M.K. Surappa, P.K Rohatgi, J. Mater. Sc., 16, 983 (1981)

5. K. Kalaiselvan, I. Dinaharan, N. Murugan, Mater. Des. 55, 176 (2014)

6. K.L. Juhasz, P. Baumli, J. Sytchev, G. Kaptay, J. Mater. Sci. 48, 7679 (2013)

7. A.E. Karantzalis, A. Lekatou, E. Georgatis, V. Poulas, H. Mavros, J. Mater. Eng. Perform. 19, 585 (2010)

8. Y. Birol, J. Alloy Compd. 440, 108 (2007)

9. A.R. Kennedy, A.E. Karantzalis, Mater. Sci. Forum 217-222, 253 (1996)

10. A.E. Karantzalis, A. Lekatou, E. Georgatis, T. Tsiligiannis, H. Mavros, J. Mater. Eng. Perform. 19, 1268 (2010)

11. A. Simon, D. Lipusz, P. Baumli, P. Balint, G. Kaptay, G. Gergely, A. Sfikas, A. Lekatou, A. Karantzalis, Z. Gacsi, Arch. Metall. Mater. 60, 1517 (2015)

12. G.B.V. Kumar, A.R.K. Swamy, A. Ramesha, J. Compos. Mater. 46, 2111 (2012)

13. A. K. Jha, R. Batham, M. Ahmed, A. K. Majumder, O. P. Modi, S. Chaturvedi, A. K. Gupta, Trans. Nonferrous Met. Soc. China 21, 32 (2011)

14. I.M. Hutchings, Int. J. Mech. Sci. 19, 45 (1977)

15. I.M. Hutchings, Mechanisms of the Erosion of Metals by Solid Particles, doi:10.1520/STP35795S

16. I. Finnie, A. Levy, D.H. McFadden, The Fundamental Mechanisms of the Erosive Wear of Ductile Metals by Solid Particles, ASTM Special Technical Publication, doi:10.1520/STP35794S

17. Q. Fang, P. Sidky, M. G. Hocking, Mater. Des., 18, 389 (1997)

18. S.K. Acharya, V. Dikshit, P. Mishra, J. Reinf. Plast. Compos. 27, 145 (2008)

19. R.A. Saravanan, I Samajdar, M.K. Surappa, Wear, 215, 223 (1998)

20. R.A. Saravanan, M.K. Surappa, B.N. Pramila Bai, Wear, 202, 154 (1997)

21. J.P. Tu, M. Matsumura, Scripta Mater., 40, 646 (1999)

22. J.P. Tu, J. Pan, M. Matsumura, H. Fukunaga, Wear, 223, 22 (1998)

23. A. Lekatou, A.E. Karantzalis, A. Evangelou, V. Gousia, G. Kaptay, Z. Gácsi, P. Baumli, A. Simon, Mater. Des. 65, 1121 (2015)

24. A.G. Lekatou, N. Gkikas, A.E. Karantzalis, G. Kaptay, Z. Gacsi, P. Baumli, A. Simon, Arch. Metall. Mater. 62, 1235 (2017)

25. A.R Kennedy, A.E Karantzalis, Mater. Sci. Eng. A-Struct., 264, 122 (1999)

26. A.E. Karantzalis, A.R. Kennedy, Mater. Sci. Tech. Ser., 14, 1092 (1998)

27. A.E. Karantzalis, S. Wyatt, A.R. Kennedy, Mater. Sci. Eng. A-Struct., 237, 200 (1997)

28. V.T. Witusiewicz, A.A. Bonder, U. Hecht, S. Rex, T.Y. Velikanova. J Alloys Compd. 465, 64 (2008)

29. P. Franke, D. Neuschotz, Thermodynamic properties of inorganic materials, Elements and binary systems from $\mathrm{Ag}-\mathrm{Al}$ to $\mathrm{Au}-\mathrm{Ti}$, Springer, 214 (2002)

30. R.H. Davies, A.T. Dinsdale, J.A. Gisby, J.A.J. Robinson, S.M. Martin, CALPHAD 26, 229 (2002)

31. N. El-Mahallawy, M.A Taha, A.E.W. Jarfors, H. Fredrikson, J Alloy Compd. 292, 221 (1999)

32. A.G. Lekatou, N. Gkikas, V. Gousia, A.E. Karantzalis, K. Lentzaris, J. Mater. Eng. Perform. (2018) (in press)

33. Y.I. Oka, S. Mihara, T. Yoshida, Wear, 267, 129 (2009) 